\title{
Prevalence of Extended Spectrum Beta-Lactamase Producing Escherichia coli and Klebsiella species from Urinary Specimens of Children attending Friendship International Children's Hospital
}

\author{
Ujjwal Rimal1 ${ }^{1}$, Shovana Thapa ${ }^{2}$, Roshani Maharjan ${ }^{1 *}$
}

${ }^{1}$ Department of Microbiology, Trichandra Multiple College, Ghantaghar, Kathmandu, Nepal. 2Department of Microbiology, International Friendship Children's Hospital, Maharajgunj, Kathmandu, Nepal

\begin{abstract}
Extended-spectrum $\beta$-lactamase producing E. coli and $K$. pneumoniae is a serious threat to the patients. These organisms are major extended spectrum beta lactamase (ESBL) producers. The objective of this study was to determine the prevalence of Extended spectrum $\beta$ - lactamase producing strains of Escherichia coli and Klebsiella spp isolates from the urine sample of children visiting International Friendship Children Hospital. During the seven months, between June 2016 to December 2016, 1018 midstream urine samples(MSU) were collected from patients suspected of having UTI. The samples were investigated by conventional semi-quantitative culture technique and identification of E. coli and Klebsiella spp. was done by microscopy and biochemical test. Antibiotic susceptibility test of isolates was performed by modified Kirby Bauer Disc diffusion test. ESBL screening test was done by using $3^{\text {rd }}$ generation Cephalosporin and confirmation done by combination disc diffusion method. Out of total 1018 MSU samples investigated, 200(19.64\%) isolates of E. coli and 28(2.7\%) isolates of Klebsiella spp. making a total of $228(22.39 \%)$ were found to cause significant bacteriuria. $76(33.33 \%)$ isolates, from those causing significant bacteriuria, were Multi-drug resistant organisms. Out of 228 isolates, 54(23.68\%) were ESBL producers, that includes 51(25.5\%) Escherichia coli and 3(12.5\%) Klebsiella pneumoniae. ESBL producers were more common in in-patient (36.17\%) than out-patient (20.44\%). Most of the ESBL producers were resistance to amoxicillin, followed by Cotrimoxazole and Ciprofloxacin respectively. They were highly sensitive to Imipenem, Tigecycline, Amikacin, Piperacillin-Tazobactam, and Nitrofurantoin. High prevalence of ESBL producing E. coli and Klebsiella pneumoniae was found among children. Regular and routine monitoring of ESBL producing isolates is essential.
\end{abstract}

Key words: Urinary tract infection(UTI), Extended spectrum beta lactamase(ESBL), E. coli, Klebsiella *Corresponding Author

E mail: roshani_mh@hotmail.com

\section{Introduction}

Urinary tract infection (UTI) is a term applied to a variety of clinical conditions ranging in severity from asymptomatic which is carrier status in the urine to symptomatic acute infection of the kidney with resultant sepsis [1]. The clinical symptoms of UTI usually include frequency, dysuria, pyuria, suprapubic tenderness, back pain, fever and urgency [2]. The most common uropathogenic Gram negative bacteria are Escherichia coli and Klebsiella pneumoniae [3].

Extended-spectrum $\beta$ lactamases (ESBLs) are a group of enzymes with the ability to hydrolyze and cause resistance to the oxyiminocephalosporins (i.e.cefotaxime, ceftazidime, ceftriaxone, cefuroxime and cefepime) monobactams (i.e. aztreonam) [4]. Beta-lactamases are among the most heterogeneous group of resistance enzymes. Despite a significant amount of amino acid sequence variability, betalactamases share a common overall topology [5]. There are several ESBLs genotypes. These are SHV, TEM, and CTX-M [6]. Other clinically important genotypes include OXA, VEB, PER, BES-1, BEL-1, SFO-1, TLA, and IBC [7]. "Classical” ESBLs are derived from TEM and SHV enzymes whereas "Non-Classical" ESBLs are derived from enzymes other than TEM or SHV. $90 \%$ of ampicillin resistance in $E$. coli is due to the production of TEM-1 [8]. Based on different combinations of changes, currently, 195 TEM-type enzymes have been described. TEM-2, the first variant described, differed from TEM-1 through the substitution of a lysine for a glutamine at position 39 [6]. A shift in the distribution of different ESBLs has recently occurred in Europe, with a dramatic increase of CTX-M enzymes over 32

Nepjol.info/index.php/njb 
TEM and SHV variants [9]. Since 2000, E. coli producing CTX-M $\beta$-lactamases have emerged worldwide as an important cause of communityonset urinary tract infections (UTIs) and this has been called the CTX-M pandemic [10]. These enzymes were named for their greater activity against cefotaxime than other oxyimino-betalactam substrates (e.g. ceftazidime, ceftriaxone, or cefepime) [7]. Rather than arising from mutation, they represent examples of plasmid acquisition of beta-lactamase genes normally found on the chromosome of Kluyvera species, a group of rarely pathogenic commensal organisms [9]. In France, a novel derivative of OXA-10 (numbered OXA-28) was found in a $P$. aeruginosa isolate [11]. The rapid increasing rate of ESBL production among Enterobacteriaceae, mainly E. coli and Klebsiella pneumonia, have created a serious global public health problem [12]. Availability of limited treatment options for the infections caused ESBL producing bacteria makes the treatment very difficult and often results into treatment failure [13]. Scant number of studies had been reported from Nepal assessing the ESBL producers among E. coli and Klebsiella spp in children. Hence the study was carried out to determine the prevalence of ESBL producing Escherichia coli and Klebsiella spp isolates from the urine samples of children.

\section{Materials and Methodology Sample collection and identification of bacteria}

The cross-sectional study was carried out in Pathology Department of International Friendship Children Hospital, Maharajgunj, Kathmandu from June 2016 to December 2016. Patients under the age of 13 years or their guardians visiting the Pathology Department were directly interviewed for his/her clinical history during the sample collection. During the study period, 1018 midstream urine samples were collected and processed according to the standard laboratory methods by Forbes et al [14]. Semi-quantitative culture technique was used to detect the presence of significant bacteriuria. The bacterial culture was done on MacConkey Agar (MA) and Blood Agar (BA) and incubated overnight at $37^{\circ} \mathrm{C}$ for isolation of pure culture. Diagnosis of UTI was made when there were colony count exceeding $10^{5}$ $\mathrm{cfu} / \mathrm{ml}$ of urine specimen. The isolates were identified based on morphology, gram's staining, motility, and standard biochemical tests as described in Forbes et al [14].

Modified Kirby-Bauer's disc diffusion method was employed for the antibiotic susceptibility test of potential pathogenic isolates as per standard technique on Muller Hilton Agar [15]. Nitrofurantoin(300mcg), Amoxicillin (30mcg), Cotrimoxazole (25 mcg), Ciprofloxacin (5mcg), Ceftriaxone (30 mcg), Ceftazidime (30 mcg), Gentamicin (10 mcg), Imipenem (10 mcg) and Meropenem (10 mcg) were used for antimicrobial susceptibility testing.

\section{Screening of ESBL producing strains of $E$. coli and K.pneumoniae}

The screening test for the production of ESBL was

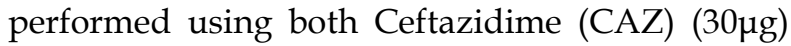
and Ceftriaxone (CTR) $(30 \mu \mathrm{g})$ disks. If the zone of inhibition was less than or equal to $22 \mathrm{~mm}$ for CAZ and/or less than or equal to $25 \mathrm{~mm}$ for CTR, the isolate was considered a potential ESBL-producer as recommended by CLSI [16].

\section{Phenotypic confirmation of ESBL production}

Susceptible screened ESBL producers were subjected to combined disk test as recommended by the CLSI [16]. Combination disk method used for the confirmation of ESBL-producing strains in

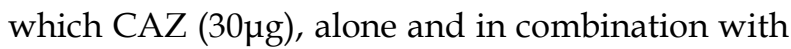
Clavulanic acid (CA) (10 $\mu$ g) were used. After incubating overnight at $37^{\circ} \mathrm{C}, \geq 5 \mathrm{~mm}$ increase in the zone diameter for either antimicrobial agent which was tested in combination with Clavulanic acid (CAC) versus its zone when tested alone, was interpreted as positive for ESBL production.

\section{Results}

Table 1: Microbiological profile of bacterial isolates

\begin{tabular}{llcc}
\hline S.N & Bacterial isolates & Number & Percent \\
\hline 1 & Escherichia coli & 200 & $82.30 \%$ \\
2 & Klebsiella pneumoniae & 24 & $10 \%$ \\
3 & Klebsiella oxytoca & 4 & $1.64 \%$ \\
4 & Citrobacter spp & 3 & $1.23 \%$ \\
5 & Pseudomonas aeruginosa & 2 & $0.82 \%$ \\
6 & Acinetobacter & 2 & $0.82 \%$ \\
7 & Staphylococcus aureus & 8 & $3.29 \%$ \\
\hline & Total & $\mathbf{2 4 3}$ & $\mathbf{1 0 0} \%$
\end{tabular}

Out of the total 1018 mid-stream urine samples, $243(23.87 \%)$ samples were found to have a significant growth. Out of 243 culture positive cases, Escherichia coli (200) (82\%) was found to be 
the most common isolates followed by Klebsiella pneumoniae (24) (10\%), Klebsiella oxytoca (4) (1.65\%), Citrobacter species (3) (1.15\%), Pseudomonas aeruginosa (2) $(0.85 \%)$, Acinetobacter species (2) $(0.85 \%)$ and the gram positive isolates, Staphylococcus aureus (8) constitutes (3.30\%) (Table 1). Most of the patient were of age group 1-5 $(60.96 \%)$ followed by age $<1(18.42 \%)$ (Table 2$)$.

Table 2: Demographic distribution of E. coli and Klebsiella spp

\begin{tabular}{|c|c|c|c|}
\hline \multirow{2}{*}{$\begin{array}{l}\text { Age } \\
\text { group }\end{array}$} & \multicolumn{2}{|c|}{ Sex of patient } & Total \\
\hline & Male $(\%)$ & Female (\%) & \\
\hline$<1$ year & $12(28 \%)$ & $(72 \%)$ & $42(18.42 \%)$ \\
\hline $1-5$ & $49(35 \%)$ & $(65 \%)$ & $139(60.96 \%)$ \\
\hline $6-10$ & $11(34.3 \%)$ & $21 \quad(65.6 \%)$ & 32(14.03\%) \\
\hline $11-13$ & $3(20 \%)$ & $(80 \%)$ & $15(6.57 \%)$ \\
\hline Total & 75 & 153 & 228 \\
\hline
\end{tabular}

Out of 200 E. coli isolates, 169(84.5\%) isolates were sensitive to Nitrofurantoin followed by gentamycin $146(73 \%)$ and cotrimoxazole $110(55 \%)$. More than $30 \%$ isolates were resistant to third generation cephalosporins i.e Ceftriaxone and Ceftazidime (Table 3).

Table 3: Antibiotic susceptibility pattern of Escherichia coli

\begin{tabular}{lccccc}
\hline \multirow{3}{*}{ Antibiotics } & \multicolumn{4}{c}{ Susceptibility pattern $(\mathrm{n}=200)$} \\
\cline { 2 - 6 } & \multicolumn{2}{c}{$\begin{array}{l}\text { Sensitive } \\
(\%)\end{array}$} & \multicolumn{2}{c}{$\begin{array}{l}\text { Intermediate } \\
(\%)\end{array}$} & \multicolumn{2}{l}{$\begin{array}{l}\text { Resistance } \\
(\%)\end{array}$} \\
\hline Amoxicillin & $14(7)$ & $23(11.5)$ & $163(81.5)$ \\
Ciprofloxacin & $91(45.5)$ & 31 & $(15.5)$ & 78 & $(39)$ \\
Cotri-moxazole & $110(55)$ & 22 & $(11)$ & 68 & $(34)$ \\
Nitrofurantoin & $169(84.5)$ & 20 & $(10)$ & 11 & $(5.5)$ \\
Gentamycin & $146(73)$ & 21 & $(10.5)$ & 33 & $(16.5)$ \\
Ceftriaxone & $108(54)$ & 30 & $(15)$ & 62 & $(31)$ \\
Ceftazidime & $98(49)$ & 34 & $(17)$ & 68 & $(34)$ \\
\hline
\end{tabular}

Out of total 24K. pneumoniae isolates, 19(79.2\%) were sensitive towards Gentamycin, followed by Nitrofurantoin 17 (71\%), Ciprofloxacin 16 (67\%) and Ceftriaxone 16 (67\%) (Table 4).

Table 4: Antibiotic susceptibility pattern of $K$. pneumoniae isolates.

\begin{tabular}{|c|c|c|c|c|}
\hline \multirow{3}{*}{$\begin{array}{l}\text { Antibiotics } \\
\text { Amoxicillin }\end{array}$} & \multicolumn{4}{|c|}{ Susceptibility pattern $(n=24)$} \\
\hline & $\begin{array}{l}\text { Sensitive } \\
(\%)\end{array}$ & $\begin{array}{l}\text { Intermediate } \\
(\%)\end{array}$ & \multicolumn{2}{|c|}{$\begin{array}{l}\text { Resistance } \\
(\%)\end{array}$} \\
\hline & $\begin{array}{ll}0 & (0)\end{array}$ & $\begin{array}{ll}0 & (0)\end{array}$ & 24 & $(100)$ \\
\hline Ciprofloxacin & $16(67)$ & $4 \quad(17)$ & 4 & $(17)$ \\
\hline Cotrimoxazole & $14 \quad(58)$ & $3 \quad(13)$ & 7 & $(29)$ \\
\hline Nitrofurantoin & $17(71)$ & $1 \quad(4)$ & 6 & (25) \\
\hline Gentamycin & $19 \quad(79.2)$ & $3 \quad(12.5)$ & 2 & $(8.3)$ \\
\hline Ceftriaxone & $16 \quad(67)$ & $2 \quad(8)$ & 6 & (25) \\
\hline Ceftazidime & $14 \quad(58)$ & $4 \quad(17)$ & 6 & (25) \\
\hline
\end{tabular}

Among total $4 \mathrm{~K}$. oxytoca isolates, all 4 were resistant to Amoxicillin, howeversensitive to Nitrofurantoin., 3 (75\%) of them were sensitive to to Cotrimoxazole, followed by ciprofloxacin. 68
(34\%) of E. coli isolates, 6(25\%) of Klebsiella pneumoniae isolates and $2(50 \%)$ of Klebsiella oxytoca isolates, making a total of $76(33.33 \%)$ isolates were Multi-drug resistant (Table 5).

Table 5: Distribution of MDR isolates

\begin{tabular}{lclc}
\hline Bacterial isolates & Total & \multicolumn{2}{c}{ MDR (\%) } \\
\hline Escherichia coli & 200 & 68 & $(34 \%)$ \\
Klebsiella pneumoniae & 24 & 6 & $(25 \%)$ \\
Klebsiella oxytoca & 4 & 2 & $(50 \%)$ \\
\hline Total & $\mathbf{2 2 8}$ & $\mathbf{7 6 ( 3 3 . 3 3 \% )}$ \\
\hline
\end{tabular}

Out of 228 isolates, 61 isolates gave ESBL screening test positive. 51 isolates of E. coli and 3 isolates of Klebsiella pneumoniae making a total of $54(23.68 \%)$ were confirmed as ESBL producers. None of K. oxytoca was ESBL producer (Table 6).

Table 6: Detection of ESBL by combination disk method.

\begin{tabular}{lccc}
\hline Organism & $\begin{array}{l}\text { Significant } \\
\text { growth }\end{array}$ & $\begin{array}{l}\text { Screening } \\
\text { test } \\
\text { positive }\end{array}$ & $\begin{array}{l}\text { Confirmatory } \\
\text { test(combination } \\
\text { disk method) }\end{array}$ \\
\hline $\begin{array}{l}\text { Increase in } \\
\text { diameter } \geq 5 \mathrm{~mm}\end{array}$ \\
\hline $\begin{array}{l}\text { Escherichia } \\
\text { coli }\end{array}$ & 200 & 57 & $51(25.5 \%)$ \\
$\begin{array}{l}\text { Klebsiella } \\
\text { pneumonia } \\
\begin{array}{l}\text { Klebsiella } \\
\text { oxytoca }\end{array}\end{array}$ & 24 & 4 & $3(12.5 \%)$ \\
\hline Total & 228 & 61 & - \\
\hline
\end{tabular}

Out of 75 isolates from male, 12(16\%) were ESBL producer and out of 153 isolates from female 42(27.54\%) were ESBL producer. More female was infected as compared to male, also chi-square test suggests a significant association in between sex of a patient and ESBL producers $(p-v a l u e<0.05)$ (Table 7).

Table 7: Gender wise distribution of ESBL producing isolates.

\begin{tabular}{lllll}
\hline Sex & $\begin{array}{l}\text { ESBL } \\
\text { producer }\end{array}$ & $\begin{array}{l}\text { ESBL non- } \\
\text { producer }\end{array}$ & Total & p-value \\
\hline Male & $12(16 \%)$ & $63(84 \%)$ & 75 & $<0.05$ \\
Female & $42(27.45 \%)$ & $111(72.54 \%)$ & 153 & \\
\hline Total & $54(23.68 \%)$ & $174(76.31 \%)$ & 228 & \\
\hline
\end{tabular}

Among culture positive cases, 47 were from Inpatient and remaining 181 were from out-patient. Among 47 In-patient, 17(36.17\%) was found to be ESBL positives. Similarly, among 181 Out-patient, $37(20.44 \%)$ was found to be ESBL positives (Table 8). All 51 ESBL producing isolates of E. coli were sensitive to Imipenem, Piperacillin-tazobactam, Tigecycline and Amikacin. 94.2\% and 92.2\% of E. coli were resistant to Ceftriaxone and Ceftazidime, respectively. 
Table 8: Department wise distribution of ESBL producers.

\begin{tabular}{lcccc} 
& In-patients & Out-patients & Total & p-value \\
\cline { 2 - 5 } $\begin{array}{l}\text { ESBL } \\
\text { producer }\end{array}$ & $17(36.17 \%)$ & $37(20.44 \%)$ & 54 & $<0.05$ \\
$\begin{array}{l}\text { ESBL non- } \\
\text { producer }\end{array}$ & $30(63.82 \%)$ & $144(79.55 \%)$ & 174 & \\
\hline Total & 47 & 181 & 228 & \\
\hline
\end{tabular}

Furthermore, $88.2 \%$ and $31.4 \%$ of E. coli were resistant to Cefepime and Meropenem, respectively (Table 9). All of the 3 ESBL producing K. pneumoniae isolates were sensitive to Imipenem, Meropenem, Piperacillin-tazobactam, tigecycline, and Amikacin. All of the isolates were resistant to Cefepime and Amoxicillin.

Table 9: Antibioitic susceptibility pattern of ESBL producing strain of $E$. coli

Antibiotics

\begin{tabular}{|c|c|c|c|c|}
\hline & Sensitive & $\begin{array}{c}\text { Sensitive } \\
\%\end{array}$ & Resistance & $\begin{array}{l}\text { Resistance } \\
\%\end{array}$ \\
\hline Amoxicillin & - & - & 51 & 100 \\
\hline Ciprofloxacin & 13 & 25.5 & 38 & 74.5 \\
\hline Cotrimoxazole & 13 & 25.5 & 38 & 74.5 \\
\hline Nitrofurantoin & 48 & 94.1 & 3 & 5.9 \\
\hline Gentamicin & 32 & 66.7 & 19 & 37.3 \\
\hline Ceftriaxone & 3 & 5.9 & 48 & 94.1 \\
\hline Ceftazidime & 4 & 7.8 & 47 & 92.2 \\
\hline Imipenem & 51 & 100 & 0 & 0 \\
\hline Meropenem & 35 & 68.6 & 16 & 31.4 \\
\hline Cefepime & 6 & 11.8 & 45 & 88.2 \\
\hline Piperacillin & 51 & 100 & - & - \\
\hline Tigecycline & 51 & 100 & - & - \\
\hline Amikacin & 51 & 100 & - & - \\
\hline
\end{tabular}

\section{Discussion}

Out of 1018 mid-stream urine sample, 243 $(23.87 \%)$ showed significant growth. Similar result was obtained by Bhandari (2013) where growth positivity was found to be $23.36 \%$ [17]. Similarly, the study carried out in India by Niranjan et al (2014) yielded $18.5 \%$ significant growth [18]. However, our result is low as compared to that reported from South Africa (51\%) by Habte et al (2009) [19]. A study conducted in Nepal by Bhatta et al (2013), demonstrated similar result with $27.3 \%$ significant growth [20]. The rate of infection found in female patients was $163 / 684(23.83 \%)$ and in male, the rate of infections was found to be 80/354 (22.59\%). There wasn't any huge difference between rate of infection in male and female children patient. This result is in contrast to the earlier studies by Thakur et al (2013) where 56.64\% female and $43.36 \%$ male patient were infected [21]. The growth positivity with $33.5 \%$ among female patients and $23.7 \%$ in male patients was observed in a similar study by Baral et al (2012)[22].

The predominant isolate was E. coli $(82.30 \%)$ followed by Klebsiella species (11.53\%) and Staphylococcus aureus $(3.29 \%)$. E. coli is a predominant isolate, because $E$. coli can bind to the glycol-conjugate receptor of the uroepithelial cells of human urinary tract so it can initiate infection itself. E. coli is isolated in $90 \%$ of infection and strains are characterized by presence of unique virulence determinant the pilus (Gal-Gal) receptor [23]. Similar result was obtained by other studies [24, 25].

E. coli was found to be resistant towards amoxicillin $(81.5 \%)$, Co-trimoxazole $(35 \%)$, and Ciprofloxacin (38\%). In our study, $25 \%$ of $K$. pneumoniae were resistant to both Ceftriaxone and Ceftazidime. Other studies from Nepal reported that the resistance rates of $K$. pneumoniae to thirdgeneration Cephalosporin were between 20\% to $75 \%[26,27]$.

Likewise, $25 \%$ and $8.3 \%$ of K. pneumoniae were found resistant to Nitrofurantoin and Gentamicin, respectively. All K. pneumoniae strains were resistant $(100 \%)$ to Amoxicillin, while resistance rate for $E$. coli was $81.5 \%$. Similar result was observed in a study carried out at Madagascar, where $80 \%$ of the $E$. coli isolates were resistant to amoxicillin [28]. In our study, E. coli showed a high resistance rate $68 \%$ to Co-trimoxazole whereas the K. pneumoniae showed resistance rate $30 \%$ to Co-trimoxazole. A comparable resistance rate of $80 \%$ and $45 \%$ to Cotrimoxazole was shown among ESBL producing E. coli and K. pneumoniae isolates in a study conducted in Iran [29]. Bazzaz et al (2009) reported ESBL-producing isolates of $K$. pneumoniae and E. coli as 59.2\% [30].

In this study, $17 \%$ isolates of K. pneumoniae were resistant to Ciprofloxacin. Resistant to fluoroquinolones is due to the result of alterations in target enzyme (DNA gyrase and topoisomerase IV) and because of change in drug entry and efflux [31]. Klebsiella pneumoniae sensitivity towards Gentamicin was found in $79.2 \%$ which was significantly higher than that was reported in Karanchi, Pakistan where a resistance rate for gentamicin was $46.7 \%$ [32]. However, the rate was only slightly higher than to the findings from previous study done in Nepal where the sensitivity was $72.9 \%$ [22]. These significant variations may be attributed to selective pressures 
by drugs in different regions. Resistance of aminoglycosides is done by the enzymes that cause modification of drug by phosphorylation, acetylation or adenylation and less or more by other methods [33].

In our study, $31.4 \%$ of ESBL positive E. coli was resistant to Meropenem, whereas all isolates were sensitive to Imipenem which is similar to the study done in Peshawar, Pakistan [34]. The emergence of carbapenem resistance in $K$. pneumoniae is typically attributed to the production of Klebsiella pneumoniae carbapenemase (KPC) [35].

We found the 76 (33.33\%) isolates of E. coli and Klebsiella spp were multidrug resistant. Similar findings were observed in the study done by Tuladhar et al (2003), in a hospital in Kathmandu, where $35.21 \%$ of bacterial strain were MDR [36]. But the result was in contrast to the study by Upadhaya et al (2013) where $48 \%$ were MDR [37]. The prevalence of MDR varied among different studies and outcome of the prevalence may depend on various factors such as MDR criterion, how the antibiotics are used, and organism encoding multiple resistance gene which is becoming more prevalent.

Out of 228 isolates, 54 (23.68\%) were ESBL producer. Our finding was lower in comparison to the study conducted by Dahal et al (2016), in a community hospital of Kathmandu that reported $47.75 \%$ as ESBL producer [25]. A study done in India reported nearly $40 \%$ of urinary isolates of $E$. coli and K. pneumoniae were ESBL positive [38]. Our result was similar to the study done by Poudyal (2010) where 25.7\% ESBL producer were isolated from urine sample [39]. However, our result showed higher prevalence as compared to the study by Logan et al (2014) in the United States with ESBLs representing only $0.28 \%$ of all E. coli, $K$. pneumoniae, and P. mirabilis in children from 1999 to 2001 and later increasing to $0.92 \%$ of all isolates in 2010-2011 [40]. The occurrence of ESBLs among clinical isolates varies greatly from country to country, among the hospitals, within the country.

In our study, $25.5 \%$ of $E$. coli isolates and $12.5 \%$ of Klebsiella pneumoniae isolates were ESBL producer. These findings were comparable to the study done by Chander and Shrestha (2013) in Nepal tertiary hospital in which $13.51 \%$ of E. coli and $16.55 \%$ of Klebsiella pneumoniae were ESBL producers [41].
ESBL occurrence among E. coli and Klebsiella is of great concern since infections caused by these bacteria are very common and resistance of the organism may be due to the presence of capsule that gives some level of protection to the cells, presence of multidrug resistance efflux pump, they also spread easily, are pathogenic and efficient at acquiring and disseminating resistance plasmid [42]. More female $(27.45 \%)$ were infected as compared to male $(16 \%)$. Similar result was obtained by Bhandari (2013) [17].

Though some of our results were very much contrast with other studies, the prevalence rate of ESBL producing isolates in our study was considered significant and high. The higher number of ESBL producers might be due to more reliance on third generation Cephalosporins to treat Gram negative infections and unscrupulous hospital antibiotic policy. Moreover, high prevalence of ESBL isolates among children might be due to immaturity of the immune system in these infection in these age group. Further studies are required to know the current burden in these population.

\section{Conclusion}

High prevalence of ESBL producing E. coli and $K$. pneumoniae was observed in our study.

E. coli is predominant ESBL producers than $K$. pneumoniae. Children under age five were found to be highly infected with urinary tract infection. Escherichia coli and Klebsiella spp are emerging highly as a multi-drug resistant. Imipenem, Tigecycline, Amikacin, Piperacillin-Tazobactam were found to be the most effective drug against the ESBL producing isolates. Nitrofurantoin and Gentamycin can be used as a drug of choice against non-ESBL producing isolates.

\section{DECLARATION \\ Ethics approval and consent to participate}

Ethical approval was taken from the Ethical Review committee of International Friendship Children's Hospital and Tri-Chandra Multiple Campus. Informed consent form was obtained from parents of the participants before their participation.

\section{Competing interests}

We have read Nepal journal of biotechnology policy on declaration of competing interest and declare that we have no competing interests. 


\section{Authors' contribution}

Mr. Ujjwal Rimal, Mrs. Roshani Maharjan, and Dr. Shovana Thapa jointly performed the study.

\section{Acknowledgement}

The authors would like to convey special thanks to staffs of International Friendship Children Hospital, participant children, their parents and to all the people who directly or indirectly helped us in completing this work.

\section{References}

1. Tanagho EA, Mcaninch JW: Smith's General Urology: Bacterial Infections of the genitourinary tract. United States of America: McGraw-Hill companies Inc, 2004, 203-227.

2. Gupta K, Hooton TM, Naber KG: International clinical practice guidelines for the treatment of acute uncomplicated cystitis and pyelonephritis in women: a 2010 update by the Infectious Diseases Society of America and the European Society for Microbiology and Infectious Diseases. Clin Infect Dis. 2011 52:103-120

3. Behzadi P, Behzadi E, Yazdanbod H, Aghapour R, Akbari Cheshmeh M, Salehian Omran D: A survey on urinary tract infections associated with the three most common uropathogenic bacteria. Maedica (Buchar). 2010 5(2):111-115.

4. Peiran G, Pitout JD: Molecular epidemiology of Escherichia coli producing CTX-M $\beta$ Lactamases: worldwide emergence of clone ST131 025:H4. International J Antimicrobial Agents. 2010 35: 316321.

5. Perez F, Endimiani A, Hujer KM, Bonomo RA: The continuing challenges of ESBLs. Current Opinion in Pharmacology. Curr Opin Pharmacol. 2007 7(5):459-469.

6. Rupp ME and Paul D: Extended Spectrum $\beta$ Lactamase (ESBL) Producing Enterobacteriaceae. Drugs. 2003 63(4):353-356.

7. Pitout JD and Laupland KB: Extended-spectrum beta-lactamase producing Enterobacteriaceae: an emerging public-health concern. The lancet Infectious Diseases. 2008 8: 159-166.

8. Sohei H, Yoshikazu I, Keizo Y: Extended-spectrum $\beta$-Lactamases: Implications for the Clinical Laboratory and Therapy. Korean J Laboratory Medicine. 2008 28:401-41.

9. Coque TM, Baquero F, Cantón R: Increasing prevalence of ESBL-producing Enterobacteriaceae in Europe. Euro Surveillance. 2008 13, 1-11

10. Gutkind G, Radice M, Gonzalez C, Power P, Vidal $\mathrm{M}$ : Third generation cephalosporin resistance in Shigella sonnei, Argentina. Emerging infectious diseases. 2001 7(3):442.

11. Poirel L, Naas T, Thomas LE, Karim A, Bingen E, Nordmann P: CTX-M-type extended-spectrum beta-lactamase that hydrolyzes ceftazidime through a single amino acid substitution in the omega loop. Antimicrob. Agents Chemother. 2001 45:3355-3361.
12. Bora A, Sanjana R, Jha BK, Mahaseth SN, Pokharel $\mathrm{K}$ : Incidence of metallo-beta-lactamase producing clinical isolates of Escherichia coli and Klebsiella pneumoniae in central Nepal. BMC Res Notes. 2014 7:557.

13. Mishra SK, Acharya J, Kattel H, Pokhrel BM, Rijal $\mathrm{BP}$ : Extended-spectrum beta-lactamase and metallo-beta-lactamase-producing bacterial strains among the patients attending a tertiary care center in Nepal. Int J Infect Dis. 2012. 16:425.

14. Forbes BA, Sahm DF and Weissfeld AS: Bailey and Scott's Diagnostic Microbiology 12th edition. Mosby Elsevier Publication, USA; 2007, 350-362.

15. CLSI: Performance Standards for Testing; Twenty-First Informational Supplement. CLSI document M100-S21. Clinical and Laboratory Standards Institute, Wayne (PA). 2011.

16. CLSI: Performance standards for antimicrobial susceptibility testing; Twenty-fourth informational supplement. M100 S24. Clinical and Laboratory Standards Institute, Wayne (PA). 2014.

17. Bhandari P: Prevalence of ESBL produccing Escherichia coli from urine sample of the patients visiting venus internation hospital, Kathmandu. Msc Thesis. Tribhuvan University, submitted to department of microbiology, St. Xaviers college, 2013.

18. Niranjan V, Malini A: Antimicrobial resistance pattern in Escherichia coli causing urinary tract infection among inpatients. Indian $J$ Medical Research. 2014, 139:945-8.

19. Habte TM, Dube S, Ismail N, Hoosen AA: Hospital and community isolates of uropathogens at a tertiary hospital in South Africa. South Africa Medical J. 2009 99:584-587.

20. Bhatta DR, Shrestha J, Sharma AR, Banjara MR: Antimicrobial Susceptibility Pattern of Escherichia coli Isolated from Urinary Tract Infected Patients Attending Bir Hospital. Nepal. J Science and Technology. 2013 14(1): 177-184.

21. Thakur S, Pokhrel N and Sharma M: Prevalence of Multidrug Resistant Enterobacteriaceae and Extended Spectrum $\beta$ Lactamase Producing Escherichia Coli in Urinary Tract Infection. Research J Pharmaceutical, Biological and Chemical Sciences. 20134 (2):1615.

22. Baral P, Neupane S, Marasini BP, Ghimire KR, Lekhak B, Shrestha B: High prevalence of multidrug resistance in bacterial uropathogens from Kathmandu, Nepal. BMC Research Notes. 20125:38.

23. Kot B, Wicha J, Zak-Palawska Z: Susceptibility of Escherichia coli strains isolated from persons with urinary tract infections in 2007-2008 to microbial agents. Przegl Epidemol. 2010 64:307-312.

24. Raza S, Pandey S, Bhatt CP: Microbiological Analysis of the Urine Isolates in Kathmandu Medical College Teaching Hospital, Kathmandu, Nepal. Kathmandu Univ Med J. 2011 36(4):295-7.

25. Dahal S, Singh A, Sharma S, Awal BK: Extended spectrum b lactamase producing Multidrug resistant Escherichia coli at community hospital of kathmandu. Tribhuvan University J Microbiol. 2016 3(1) 55-60 
26. Sherchan JB, Gurung P, Bam DS: Multi-drug resistant bacterial strains in lower respiratory tract infections, antibiotic sensitivity patterns and risk factor. Nepal J science and technology. 2012 13(1):157-163.

27. Mishra MP, Debata NK, Padhy RN: Surveillance of multi-drug resistant uropathogenic bacteria in hospitalized patient in Indian. Asian Pacific $J$ tropical biomedicine. 2013 3(4):315-324.

28. Randrianirina F, Soares JL, Carod JF, Ratsima E, Thonnier V, Combe P: Antimicrobial resistance among uropathogens that cause communityacquired urinary tract infections in Antananarivo, Madagascar. J Antimicrob Chemother. 2007 59:309-312.

29. Behrooozi A, Rahbar M, Yousefi JV: Frequency of extended spectrum beta-lactamase (ESBLs) producing Escherichia coli and Klebsiella pneumoniae isolated from urine in an Iranian 1000-bed tertiary care hospital. African J Microbiol Research. 2010 4(9):881-884.

30. Bazzaz BS, Naderinasab M, Mohamadpoor AH, Farshadzadeh Z, Ahmadi S, Yousefi F: The prevalence of extended-spectrum beta-lactamaseproducing Escherichia coli and Klebsiella pneumoniae among clinical isolates from a general hospital in Iran. Acta Microbiol Immunol Hung. 2009 56(1):89-99.

31. Jacoby GA: Mechanism of resistance to quinolones. Clinical Infectious Disease. 2005, 41:120-126.

32. Abdullah FE, Mushtaq A, Irshad M, Rauf H, Afzal $\mathrm{N}$, Rasheed A: Current efficacy of antibiotics against Klebsiella isolates from urine samples - a multi-centric experience in Karachi. Pakistan J Pharmaceutical Sci. 2013 26(1):11-15

33. Davis MA, Baker KN, Orfe LH, Shah DH, Besser TE, Call DR: Discovery of a Gene Conferring Multiple-Aminoglycosides Resistance in Escherichia coli. Antimicrobial Agents Chemother. 2010 54:266-2669.

34. Ullah F, Malik SA, Ahmed J: Antibiotic susceptibility pattern and ESBL prevalence in nosocomial Escherichia coli from urinary tract infections in Pakistan. African J Biotechnology. 2009 8(16): 3921-3926.

35. Nordmann P, Cuzon G, Naas T: The real threat of Klebsiella pneumoniae carbapenemaseproducing bacteria. Lancet Infectious Disease. 2009 9: 228-236.

36. Tuladhar NR, Banjade N, Pokhrel BM, Rizal B, Manandhar R, Shrestha S, Shah A and Chaurasia S: Antimicrobial resistant bacterial strains from inpatients of Tribhuvan University teaching hospital Kathmandu. J Inst Med. 2003 25:19-26.

37. Upadhyay G, Shakya G, Upadhyaya BP, Shrestha S, Ansari S, Ghimire $\mathrm{P}$ et al: Comparative evaluation of urine isolates among kidney transplanted and other UTI suspected patients visiting National Public Health Laboratory, (NPHL) Teku, Nepal. Int J Biomed Adv Res. 2013 4(6):369-75.

38. Babypadmini S, Appalaraju B: Extended spectrum lactamase in urinary isolates of $E$. coli and Klebsiella pneumoniae- prevalence and susceptibility patterns in a tertiary care hospital. Indian J Medical Microbiol. 2004 22:172174.

39. Poudyal S: Prevalance of $\mathbf{b}$ lactamase producing multidrug resistant bacterial pathogens isolated from different clinical samples at National public health laboratory, Nepal. Msc Thesis. Tribhuvan University, submitted to Central Department of microbiology. 2010

40. Logan LK, Braykov NP, Weinstein RA, Laxminarayan R. Extended-spectrum betalactamase-producing and third-generation cephalosporin-resistant Enterobacteriaceae in children: trends in the United States, 1999-2011. J Pediatr Infect Dis Soc. 2014 3:320-8.

41. Chander A, Shrestha CD: Prevalence of extended spectrum beta-lactamase producing Escherichia coli and Klebsiella pneumoniae urinary isolates in tertiary care hospital in Kathmandu, Nepal. BMC Research notes. 2013 6(1):487

42. Chudhary U and Aggarwal R: Extended spectrum $b$ lactamase (ESBL)- an emerging threat to clinical therapeutics. Indian J Med Microbiol Rev. 2004 22: 75-80 